\title{
Changing Pharmaceutical Industry Interaction in US Family Medicine Residencies: A CERA Study
}

\author{
Steven R. Brown, MD, FAAFP and Adriane Fugh-Berman, MD
}

Background: Pharmaceutical interaction in US residencies is common. This study explores the extent and type of learner interactions in US family medicine residencies with the pharmaceutical industry and compares interactions from 2008, 2013, and 2019.

Methods: We surveyed program directors of 628 family medicine residencies with 8 questions using the 2019 Council of Academic Family Medicine Educational Research Alliance Survey and compared the responses to 2008 and 2013 results.

Results: The survey response rate was $39 \% ; 81 \%$ of responding residencies did not allow food or gifts, $86 \%$ did not allow drug samples, $84 \%$ did not allow industry to interact with medical students or residents, and $81 \%$ did not allow industry-sponsored residency activities. These numbers were statistically significantly higher than both 2008 and 2013. In 2019, 151 responding programs (64\%) were pharma-free, that is, they answered "No" to all 4 questions about interactions. Pharma-free residencies were increased in 2019 compared with $26 \%$ in $2008 \%$ and $49 \%$ in 2013 . University-based family medicine programs were more likely to be pharma-free. Only $21 \%$ of responding programs had a formal curriculum that explores the interaction between physicians and the pharmaceutical industry. Factors cited for decreasing interaction included: institutional policy, ethical concerns, faculty input, and local response to national legislation.

Conclusions: Interaction between trainees in US family medicine residencies and the pharmaceutical industry continued to decrease. A changing national legislative landscape combined with institutional policies and concerns about industry influence on prescribing habits may be important factors driving the limiting of interactions. ( $\mathrm{J}$ Am Board Fam Med 2021;34:105-112.)

Keywords: Conflict of interest, Drug Industry, Family Medicine, Graduate Medical Education, Internship and Residency, Marketing, Organizational Policy, Pharmaceutical Economics, Surveys and Questionnaires

\section{Introduction}

Pharmaceutical industry interactions are common in medical schools and residency training programs. ${ }^{1}$ Many residents (54\% in 1 recent survey) have accepted gifts or food. ${ }^{2}$ Residency programs in multiple specialties allow food and other gifts, as well as industry sponsorship of lectures, journal clubs, and other events. ${ }^{2-5}$ A 2011 survey of medical students

This article was externally peer reviewed.

Submitted 11 June 2020; revised 23 August 2020; accepted 24 August 2020.

From the Family Medicine Residency, University of Arizona College of Medicine, Phoenix, Phoenix, AZ (SRB); Department of Pharmacology and Physiology and Department of Family Medicine, Georgetown University Medical Center, Washington, $\mathrm{DC}(\mathrm{AFB})$.

Funding: None.

Conflict of interest: None.

Corresponding author: Steven R. Brown, MD, FAAFP, Banner Good Samaritan Family Medicine Residency, 1300 N 12th St. Suite 605, Phoenix, AZ 85006 (E-mail: Steven. Brown@bannerhealth.com). and residents found that $49 \%$ of residents had met with pharmaceutical representatives, and $36 \%$ had attended industry-sponsored lectures. ${ }^{2}$ The more contact learners have with industry, the more positively they felt about industry interactions. ${ }^{6,7}$

Industry gifts to physicians are common ${ }^{8-10}$ and interactions with the pharmaceutical industry affect physician attitudes and prescribing behavior. ${ }^{71-18}$

Prescribing habits are formed during medical training. Nonrational prescribing is associated with trainee exposure to industry promotion. ${ }^{6,7}$ Access to drug samples, an important form of promotion, also changes physician prescribing patterns. ${ }^{19-22}$

There are few studies from the past 15 years on the quantity of pharmaceutical interaction with residents. A survey of US internal medicine residency program directors in 2006 to 2007 found that $56 \%$ accepted support from industry. ${ }^{3}$ A survey of 122 ophthalmology residency programs in the United States found that drug reps visited 
$87 \%$ of programs at least monthly; most respondents had accepted gifts. ${ }^{5}$ In a 2009 study of surgical residency training programs about two thirds reported industry-sponsored meals. ${ }^{4}$ In colorectal surgery programs in 2013, 69\% of program directors and $60 \%$ of other faculty received 1 or more payments in the last half of 2013. Fourty-nine (93\%) programs had surgeons who received funding. ${ }^{23}$

Some medical schools and residency programs teach formal curricula on physician-pharmaceutical industry interactions. ${ }^{24}$ In 2013, 4 in 10 family medicine residency programs had such a curriculum. ${ }^{25}$ Curricula are more common in residencies that allowed interaction with industry (52\%) compared with the residencies that did not allow interaction with industry $(30 \%){ }^{25}$

There is evidence that physician-industry interaction in the United States is decreasing. A 2009 survey showed that physician interactions with industry had decreased since 2004, although $84 \%$ of physicians still had some relationship. ${ }^{10}$ From 2006 to 2009, numerous experts and national organizations called for limiting industry involvement in training programs. ${ }^{26-29}$ The Sunshine Provision of the 2010 Affordable Care Act required the pharmaceutical industry, starting in 2014, to report payments and gifts to teaching hospitals and physicians. Required reporting may limit interactions and gifts. ${ }^{15,30}$

Revised standards addressing commercial support of continuing medical education may also be a factor in changing policy and perception, although there is ongoing controversy about whether these revisions decreased financial conflicts of interest. ${ }^{31}$ We published 2 surveys of pharmaceutical industry interactions in family medicine residencies that showed that industry interaction decreased substantially between 2008 and 2013. ${ }^{32-33}$ Residency programs declined more gifts or industry-sponsored food $(48 \%$ to $73 \%)$ and increased refusal of sample medications (52\% to $78 \%$ ). Fewer programs allowed industry representatives to have access to learners ( $43 \%$ to $74 \%$ ). Residency programs that forbade industry-sponsored activities remained stable over the 5 -year time period ( $67 \%$ vs $73 \%$ ).

In 2019 , we surveyed family medicine residency program directors to determine whether the trend of decreasing industry interactions has continued since 2013 and to assess changes in pharmaceutical industry interaction.

\section{Methods}

The 2019 survey of program directors of US family medicine residencies was conducted as part of a larger omnibus survey, the Council of Academic Family Medicine Educational Research Alliance (CERA) Program Director Survey. The methodology of the CERA Program Director Survey has previously been described in detail. ${ }^{34}$ The CERA steering committee, a group with expertise in survey creation and testing, evaluated questions for consistency with the overall subproject aim, readability, and existing evidence of reliability and validity. Pretesting was done on family medicine educators who were not part of the target population. The questions were modified following pretesting for flow, timing, and readability. The project was approved by the American Academy of Family Physicians Institutional Review Board in September 2019. Data were collected from September 2019 to November 2019.

The sampling frame for the survey was all Accrediting Council of Graduate Medical Education accredited US family medicine residency program directors, as identified by the Association of Family Medicine Residency Directors. E-mail invitations to participate were delivered with the survey using the online program, Survey Monkey. Six follow-up e-mails to encourage nonrespondents to participate were sent after the initial e-mail invitation. There were 668 program directors at the time of the survey. Forty had previously opted out or blocked Survey Monkey surveys. Therefore, the survey was emailed to 628 individuals.

The survey included 8 questions related to our analysis (see Table 1).

Questions 1 to 4 were the same questions we asked in both the 2008 and 2013 surveys. We asked question 5 as a follow-up to our 2011 curriculum study, ${ }^{25}$ and questions 6 to 8 were new. We added a statement to question 3 regarding industry representatives: Note: This does not include access required for device training, such as Nexplanon. We heard from several program directors in the previous survey and subsequently that access is essential for optimal patient care and some were uncertain when answering this question. As our survey is largely regarding drug marketing, not devices, we felt adding the device statement would improve clarity.

Since our first survey, ${ }^{32}$ we've designated as "pharma-free" family medicine residencies that 
Table 1. 2019 CERA Program Director Survey Questions: Pharmaceutical Industry Interaction in US Family Medicine Residencies

\begin{tabular}{|c|c|}
\hline Survey Question & Response Options \\
\hline $\begin{array}{l}\text { Does your residency allow gifts from industry or industry- } \\
\text { supported food? }\end{array}$ & $\begin{array}{l}\text { - Yes } \\
\text { - No }\end{array}$ \\
\hline Are drug samples accepted at the residency? & $\begin{array}{l}\text { - Yes } \\
\text { - No }\end{array}$ \\
\hline $\begin{array}{l}\text { Are industry representatives allowed access to medical students } \\
\text { and/or residents at the family medicine center? (Note: This does } \\
\text { not include access required for device training, such as Nexplanon)* }\end{array}$ & $\begin{array}{l}\text { - Yes } \\
\text { - No }\end{array}$ \\
\hline Are any industry-sponsored residency activities allowed? & $\begin{array}{l}\text { - Yes } \\
\text { - No }\end{array}$ \\
\hline $\begin{array}{l}\text { Does your residency have a formal curriculum that explores the } \\
\text { interactions between physicians and the pharmaceutical } \\
\text { industry? }\end{array}$ & $\begin{array}{l}\text { - Yes } \\
\text { - No }\end{array}$ \\
\hline $\begin{array}{l}\text { In the past five years how has your program's interaction with the } \\
\text { pharmaceutical industry changed? (through samples, visits from } \\
\text { representatives, gifts/food, and sponsored activities): }\end{array}$ & $\begin{array}{l}\text { - Increased } \\
\text { - Decreased } \\
\text { - Stayed the same } \\
\text { Don't know }\end{array}$ \\
\hline $\begin{array}{l}\text { If decrease: What were the major factors that led to a decrease } \\
\text { in pharmaceutical interaction? (Pick all that apply) }\end{array}$ & $\begin{array}{l}\text { - Local response to national legislation (2013 Sunshine Act } \\
\text { requiring documentation of all gifts) } \\
\text { - Ethical concerns } \\
\text { - Resident input } \\
\text { - Faculty input } \\
\text { - Institutional policy } \\
\text { - Other }\end{array}$ \\
\hline $\begin{array}{l}\text { If increase: What were the major factors that led to an increase } \\
\text { in pharmaceutical interaction? (Pick all that apply) }\end{array}$ & $\begin{array}{l}\text { - Resident input } \\
\text { - Faculty input } \\
\text { - Need for samples } \\
\text { - Resources (e.g. food for lunches) } \\
\text { - Institutional policy } \\
\text { - Oducational factors (e.g., exposure to teach interaction) }\end{array}$ \\
\hline
\end{tabular}

*The device clarification was added in the 2019 survey based on some feedback from pre-survey peer review and our 2013 study.

answered "No" to our original 4 questions. Pharmafree programs allow no industry gifts, food, samples, interaction with students or residents, or sponsorship of residency activities.

US family medicine residencies are categorized by program type: university based, community based, university affiliated, community-based nonaffiliated, and military. Programs self reported their program type.

Chi-squared testing employing contingency tables was used to compare results among years. A 2-tailed $P<.05$ was considered significant. The data were analyzed using IBM SPSS Statistics for Macintosh v 26.0, (IBM Analytics, Armonk, NY.)

\section{Results}

The overall response rate for the 2019 CERA Program Director survey was 39\% (250/628). 237/628 (38\%) answered our questions. The response rate in our 2013 CERA survey was 56\% (251/445) and
$62 \%(286 / 460)$ in our 2008 survey (a free-standing survey unrelated to CERA).

In $2019,81 \%$ of responding residencies did not allow food or gifts, $86 \%$ did not allow drug samples, $84 \%$ did not allow industry to interact with medical students or residents, and $81 \%$ did not allow industry-sponsored residency activities. These numbers are significantly higher than both 2013 and 2008 (Figure 1$)(P<.05$ in all 4 questions comparing 2019 to 2013).

In 2019, 151 responding programs (64\%) were pharma-free, that is, they answered "no" to all 4 questions about interactions. Pharma-free residencies increased from $26 \%$ in $2008 \%$ to $49 \%$ in 2013 ( $P=.001$ comparing 2013 with 2019.)

University-based programs that responded to our survey $(40 / 51,78 \%)$ were more likely to be pharma-free than community-based universityaffiliated programs $(90 / 152,59 \%)$ and communitybased nonaffiliated programs (24/46, 52\%). Three of 4 responding military programs are pharma-free 
Figure 1. 2008, 2013, 2019 Comparison of responses of US family medicine residencies to a national survey concerning industry interactions with and access to trainees.

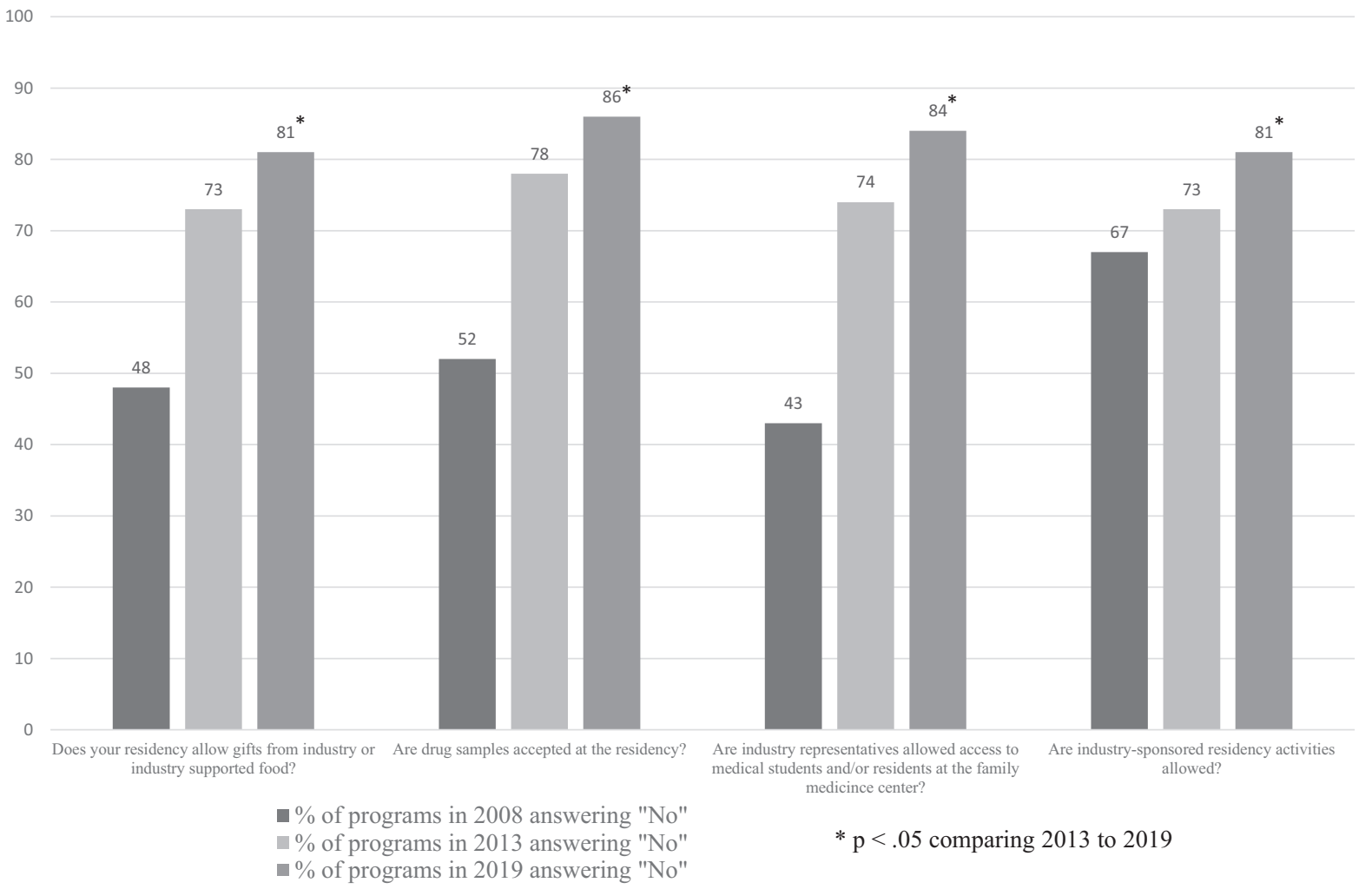

(75\%). ( $P=.02$ comparing university-based to both types of community-based programs.)

Forty-nine responding residency programs (21\%) have a formal curriculum that explores the inte-raction between physicians and the pharmaceutical industry. This is a sharp decrease from the $84(40 \%)$ reported in our 2013 curriculum study $(P<.001){ }^{25}$

Most responding program directors $(n=135$, $57 \%$ ) reported a decrease in pharmaceutical interaction in their programs within the past 5 years. Only 3 (1\%) reported an increase, while 83 (35\%) reported no change in interaction. Sixteen (7\%) did not know.

The most common factors cited for a decrease in interaction were institutional policy (mentioned by 53), ethical concerns (mentioned by 46), faculty input (mentioned by 29), local response to national legislation (mentioned by 21), and resident input (mentioned by 9).

\section{Discussion}

Interaction with the pharmaceutical industry in family medicine residencies continues to decrease.
Our 10-year follow-up study provides unique insights into changing industry relationships with residencies over time. No other studies have examined residencies in 1 specialty over 3 timepoints.

The decrease in interactions noted by responding programs was particularly marked between 2008 and 2013, but the trend continued from 2013 to 2019. Our data mirror changes among physicians in general. A 2017 survey showed that the percentage of physicians with any relationship with industry decreased from $84 \%$ in 2009 to $72 \%$ in 2017. ${ }^{10,35}$ In these studies, the number of physicians who receive drug samples decreased in 2017 compared with 2009 from $64 \%$ to $55 \%$ and the number of physicians receiving any food/beverage or tickets to cultural/sporting events decreased from $75 \%$ to $42 \%$. An analysis of prescriptions and industry funding after the Sunshine Act showed a decrease in industry payments to physicians between 2014 and 2016. ${ }^{15}$ Medical student exposure to drug company interactions decreased from 2002 to 2013 and students became more skeptical of the benefit of pharmaceutical interaction over that time period. ${ }^{36}$ 
Changes in the health care landscape have been implemented since 2009, mostly notably the Sunshine Act, and numerous experts suggested limiting interaction. $^{26-29}$ Some states have enacted strict gift bans or reporting rules. ${ }^{37}$ Until our study, there has been no recent research showing the impact of these changes on interaction in residency programs.

Most family medicine residencies (90\%) are in a community setting. ${ }^{38}$ Most of the programs (80\%) in a community setting are affiliated with or administered by a medical school, even if they are not located on the campus of an academic medical center. ${ }^{38}$ Academic medical centers and associated medical schools have been a focus of advocacy for eliminating pharmaceutical influence. ${ }^{26} \mathrm{~A}$ recent survey from the American Medical Student Association (AMSA) showed that only 4 medical schools banned pharmaceutical representatives from campus. ${ }^{39}$ It seems from our study that indeed academic medical centers are leading the way, although community programs are also majority pharma-free. Most medical students $(65 \%)$ report private outpatient offices are the main source of exposure to industry marketing. ${ }^{36}$

Our surveys, unlike the AMSA scorecard, assessed practice, not policy. More than two thirds $(70 \%)$ of medical schools now earn an "A" or "B" grade on the AMSA scorecard for their industry interaction policies. ${ }^{39}$ Policies may be ineffective: an important study shows that restrictive policies at medical schools did not make residents more likely to avoid industry interactions. ${ }^{40}$ This may be due to what has been called the "hidden curriculum," which is the example set by mentors. ${ }^{41,42}$ The AMSA scorecard may have been a factor in ongoing change in academic medical centers.

According to our study, responding program directors believe that institutional policies have played an important role in decreased interaction. Other important factors include ethical concerns and input from faculty. National legislation is also a reason cited by many of our respondents.

The Accreditation Council of Graduate Medical Education suggests residency programs should educate residents about interaction with industry. ${ }^{1}$ Presence of formal curricula in family medicine residencies is decreasing based on our data from responding program directors We are not aware of any study in another specialty that measures rate of implementation of industry interaction curricula. Evans' study of family medicine residencies found that curricula on physician- pharmaceutical industry interactions were more common in residencies that allowed industry interactions. ${ }^{25}$ Formal curricula vary widely and are not necessarily critical of industry tactics. A systematic review of 9 published curricula found inconsistencies in content, application, and evaluation methodology. ${ }^{24}$ It is plausible that residencies that allow industry interactions feel called on to have a countervailing influence. It seems unlikely, however, that a residency program that allows drug reps would inveigh against seeing drug reps. Programs that currently allow pharmaceutical interaction may find our data useful as they plan curriculum or future policy.

The drop in industry interactions we observed may be associated with the drop in formal curricula programs; residencies with few industry interactions may feel less need for a formal curriculum. Practice may be more important than policy. Pharmaceutical representatives may present inaccurate information. A study conducted in the United States, Canada, and France found that drug reps rarely mention serious adverse effects-even for drugs with black box warnings-and often promoted drugs off-label. ${ }^{4,44}$ False statements are common in conversations with drug reps. ${ }^{43}$ Pharmaceutical representatives are trained to pivot in discussion when the conversation is moving in a direction less favorable to the marketed drug. ${ }^{45}$ Howard Brody, ${ }^{46}$ a family physician and ethicist, argues that the time needed to find information to check the accuracy of pharmaceutical industry pitches far outweighs any benefit from the knowledge gained during an interaction.

Family medicine residency programs may have fewer relationships than other specialties, but this is difficult to ascertain. Degree of acceptance may vary by specialty, but direct comparisons are difficult because surveys of different specialties were done at different timepoints and using different methodologies. Further research is needed to compare interactions across specialties. Our 4 questions might be a useful approach to assess interaction in other residency specialties as there is no consensus on how to best measure pharmaceutical influence in residency programs.

Our study has several limitations. Our survey response rate of $38 \%$, was lower than in previous years. This may be due to the expansion of family medicine residencies in the past 5 years. Our 2013 survey attempted to survey 445 directors while our 2019 survey attempted to survey 628 program directors. New program directors may be less familiar with 
the CERA survey and less likely to respond. It is possible that residencies that take money, gifts or samples from industry are less likely to respond. However, as the CERA omnibus survey covers multiple topics, bias to the topic of the question may be less likely; it is unlikely the respondents would avoid answering the whole survey because of a relatively small portion of the survey The 2019 Program Director CERA omnibus survey covered 5 main topics including: simulation based medical education, vasectomy training, oncology curriculum, and HIV and Hepatitis C prevention in pregnancy. Because of the nature of the CERA survey, we are unable to compare the cohorts from year to year. There are no data on nonresponders that would allow us to know the impact this issue had on survey response. The CERA survey does not gather data on survey nonresponders; that would be useful information for an additional study. We did not assess all types of pharmaceutical influence including faculty involvement in speakers' bureaus or industry-funded Continuing Medical Education (CME), faculty participation in ghostwritten or ghostmanaged articles, or involvement in industry-sponsored research. Our survey may miss subtle interactions that influence behavior and resident learning. The effect of an exemption being added in 2013 for interactions with device reps involved in implantable contraceptives is unclear. Tactics used by device manufacturers to market devices largely mirror tactics used by drug companies to market drugs. ${ }^{47-49}$ Asking participants not to include involvement in implanted device training may have introduced an element of uncertainty for respondents.

In conclusion, pharmaceutical industry influence continues to decrease in US family medicine residencies. National policies and concerns about industry influence on physician behavior continue to transform the nature of the relationship between industry and resident trainees. Concurrently, formal curricula on industry interaction is waning. Programs may be more focused on eliminating the hidden curriculum and discouraging industry interaction than they are on formal curricular change. Residencies will continue to grapple with how best to eliminate or manage influence that leads to nonrational prescribing in a constantly changing health care and educational environment.

The authors thank Lorraine Wallace, PhD, CERA advisor; and Richard Gerkin, MD, for statistical support. The authors also thank the co-authors of the 2008 and 2013 survey publications:
David Evans, MD; Rachel Trippett, MD; Alicia Bell, MD; Paige Hatcher Dodson, MD; Anthony Fleg, MD; and Jay Siwek, MD.

To see this article online, please go to: http://jabfm.org/content/ 34/1/105.full.

\section{References}

1. Accreditation Council for Graduate Medical Education. Principles to guide the relationship between graduate medical education, industry, and other funding sources. October 2011. Available from: https://www. acgme.org/Portals/0/PFAssets/PublicationsPapers/ GME-Funding-Industry-Other-Sources.pdf Accessed February 23, 2020.

2. Austad KE, Avorn J, Franklin JM, Kowal MK, Campbell EG, Kesselheim AS. Changing interactions between physician trainees and the pharmaceutical industry: a national survey. J Gen Intern Med 2013;28:1064-71.

3. Loertscher LL, Halvorsen AJ, Beasley BW, Holmboe ES, Kolars JC, McDonald FSP. Pharmaceutical industry support and residency education: a survey of internal medicine program directors. Arch Intern Med 2010;170:356-62.

4. Nakayama DK, Bozeman AP. Industry support of graduate medical education in surgery. Am Surg 2009;75:395-400.

5. Wang Y, Adelman RA. A study of interactions between pharmaceutical representatives and ophthalmology trainees. Am J Ophthalmol 2009;148: 619-22.

6. Austad KE, Avorn J, Franklin JM, Campbell EG, Kesselheim AS. Association of marketing interactions with medical trainees' knowledge about evidence-based prescribing: results from a national survey. JAMA Intern Med 2014;174:1283-90.

7. Zipkin DA, Steinman MA. Interactions between pharmaceutical representatives and doctors in training. a thematic review. J Gen Intern Med 2005;20:777-86.

8. Marshall DC, Jackson ME, Hattangadi-Gluth JA. Disclosure of industry payments to physicians: An epidemiologic analysis of early data from the open payments program. Mayo Clin Proc 2016;91: 84-96.

9. Parikh K, Fleischman W, Agrawal S. Industry relationships with pediatricians: findings from the open payments Sunshine Act. Pediatrics 2016;137:e20154440 e20154440.

10. Campbell EG, Rao SR, DesRoches CM, et al. Physician professionalism and changes in physicianindustry relationships from 2004 to 2009. Arch Intern Med 2010;170:1820-6.

11. Fickweiler F, Fickweiler W, Urbach E. Interactions between physicians and the pharmaceutical industry generally and sales representatives specifically and their association with physicians' attitudes and 
prescribing habits: a systematic review. BMJ Open 2017;7:e016408.

12. DeJong C, Aguilar T, Tseng CW, Lin GA, Boscardin WJ, Dudley RA. Pharmaceutical industry-sponsored meals and physician prescribing patterns for Medicare beneficiaries. JAMA Intern Med 2016;176:1114-22.

13. Wazana A. Physicians and the pharmaceutical industry: is a gift ever just a gift? JAMA 2000;283: 373-80.

14. Dana J, Loewenstein G. A social science perspective on gifts to physicians from industry. JAMA 2003;290: 252-5.

15. Brunt CS. Physician characteristics, industry transfers, and pharmaceutical prescribing: empirical evidence from Medicare and the physician payment sunshine act. Health Serv Res 2019;54: 636-49.

16. Yeh JS, Franklin JM, Avorn J, Landon J, Kesselheim AS. Association of industry payments to physicians with the prescribing of brand-name statins in Massachusetts. JAMA Intern Med 2016;176:763-8.

17. Perlis RH, Perlis CS. Physician payments from industry are associated with greater Medicare Part D prescribing costs. PLoS One 2016;11: e0155474.

18. Wood SF, Podrasky J, McMonagle MA, et al. Influence of pharmaceutical marketing on Medicare prescriptions in the District of Columbia. PLoS One 2017;12:e0186060.

19. Adair RF, Holmgren LR. Do drug samples influence resident prescribing behavior? A randomized controlled trial. Am J Med 2005;118:881-4.

20. Chew LD, O’Young TS, Hazlet TK, Radley KA, Maynard C, Lessler DS. A physician survey of the effect of drug sample availability on physicians' behavior. J Gen Intern Med 2000;15:478-83.

21. Brewer D. The effect of drug sampling policies on residents prescribing. Fam Med 1998;30:482-6.

22. Boltri JM, Gordon ER, Vogel RL. Effect of antihypertensive samples on physician prescribing patterns. Fam Med 2002;34:729-31.

23. Patel SV, Klingel M, Sonoda T. An assessment of the industry-faculty surgeon relationship within colon and rectum surgical training programs. J Surg Educ 2016;73:595-9.

24. Montague BT, Fortin AH, 6th, Rosenbaum JA. systematic review of curricula on relationships between residents and the pharmaceutical industry. Med Educ 2008;42:301-8.

25. Evans DV, Waters RC, Olsen C, Stephens MB, Brown SR. Residency curricula on physician-pharmaceutical industry interaction: A CERA study. Fam Med 2016;48:44-8.

26. Brennan TA, Rothman DJ, Blank L, et al. Health industry practices that create conflicts of interest: a policy proposal for academic medical centers. JAMA 2006;295:429-33.

27. Institute of Medicine of the National Academies. Conflict of interest in medical research, education, and practice. 2009. Available from: http://www. nationalacademies.org/hmd/Reports/2009/Conflictof-Interest-in-Medical-Research-Education-andPractice.aspx. Accessed February 24, 2020.

28. Josiah Macy, Jr. Foundation. Continuing education in the health professions: improving healthcare through lifelong learning. 2008. Available from: https:// macyfoundation.org/assets/reports/publications/macy_ conted_1_7_08.pdf. Accessed February 24, 2020.

29. Association of American Medical Colleges. Industry funding of medical education, report of the AAMC Task Force. 2008. Available from: https://www.aamc. org/data-reports/faculty-institutions/report/industryfunding-medical-education. Accessed February 23, 2020.

30. Agrawal S, Brennan N, Budetti P. The Sunshine ActEffects on physicians. N Engl J Med 2013;368:2054-7.

31. Golestaneh L, Cowan E. Hidden conflicts of interest in continuing medical education. Lancet 2017; 390:2128-30.

32. Fugh-Berman A, Brown SR, Trippett R, et al. Closing the door on pharma? A national survey of family medicine residencies regarding industry interactions. Acad Med 2011;86:649-54.

33. Brown SR, Evans DV, Fugh-Berman A. Pharmaceutical industry interactions in family medicine residencies decreased between 2008 and 2013. Fam Med 2015;47:279-82.

34. Mainous AG, Seehusen D, Shokar N. CAFM Educational Research Alliance (CERA) 2011 Residency Director Survey: background, methods, and respondent characteristics. Fam Med 2012;44:691-3.

35. Kesselheim AS, Woloshin S, Lu Z, Tessema FA, Ross KM, Schwartz LM. Internal medicine physicians' financial relationships with industry: an updated national estimate. J Gen Intern Med 2019;34:195-7.

36. Sierles FS, Kessler KH, Mintz M, et al. Changes in medical students' exposure to and attitudes about drug company interactions from 2003 to 2012: a multi-institutional follow-up survey. Acad Med 2015;90:1137-46.

37. King M, Bearman PS. Gifts and influence: conflict of interest policies and prescribing of psychotropic medications in the United States. Soc Sci Med 2017;172:153-62.

38. American Academy of Family Physicians. Residency Directory. Available from: https://www.aafp. org/medical-education/directory/residency/search. Accessed August 23, 2020.

39. Carlat DJ, Fagrelius T, Ramachandran R, Ross JS, Bergh S. The updated AMSA scorecard of conflictof-interest policies: a survey of U.S. medical schools. BMC Med Educ 2016;16:202. 
40. Yeh JS, Austad KE, Franklin JM, et al. Medical schools' industry interaction policies not associated with trainees' self-reported behavior as residents: Results of a national survey. J Grad Med Educ 2015;7:595-602.

41. Sierles FS, Brodkey AC, Cleary LM, et al. Medical students' exposure to and attitudes about drug company interactions: a national survey. JAMA 2005; 294:1034-42.

42. Steinman MA, Shlipak MG, McPhee SJ. Of principles and pens: attitudes and practices of medicine house staff toward pharmaceutical industry promotions. Am J Med 2001;110:551-7.

43. Mintzes B, Lexchin J, Sutherland JM, et al. Pharmaceutical sales representatives and patient safety: a comparative prospective study of information quality in Canada, France and the United States. J Gen Intern Med 2013;28:1368-75.

44. Habibi R, Lexchin J, Mintzes B, Holbrook A. Unwarranted claims of drug efficacy in pharmaceutical sales visits: are drugs approved on the basis of surrogate outcomes promoted appropriately? $\mathrm{Br} \mathrm{J}$ Clin Pharmacol 2017;83:2549-56.

45. Fugh-Berman A, Ahari S. Following the script: how drug reps make friends and influence doctors. PLoS Med 2007;4:e150.

46. Brody H. The company we keep: why physicians should refuse to see pharmaceutical representatives. Ann Fam Med 2005;3:82-5.

47. Johnson J, Hutchison K. They know how to work it, that's their focus in life: The complex role of industry representatives in surgical innovation. J Empir Res Hum Res Ethics 2018;13:461-74.

48. O'Connor B, Pollner F, Fugh-Berman A. Salespeople in the surgical suite: relationships between surgeons and medical device representatives. PLoS One 2016; 11:e0158510.

49. Pollner F, O'Connor B, Fugh-Berman A. Should medical device representatives assist surgeons? J Eval Clin Pract 2019;25:977-9. 